\title{
A two-stage translocation strategy for improving juvenile survival of Hawaiian monk seals
}

\author{
Jason D. Baker ${ }^{1, *}$, Albert L. Harting ${ }^{2}$, Charles L. Littnan ${ }^{1}$ \\ ${ }^{1}$ Pacific Islands Fisheries Science Center, National Marine Fisheries Service, NOAA, 2570 Dole Street, \\ Honolulu, Hawaii 96822-2396, USA \\ ${ }^{2}$ Harting Biological Consulting, 8898 Sandy Creek Lane, Bozeman, Montana 59715, USA
}

\begin{abstract}
We propose a two-stage translocation strategy to conserve metapopulations of endangered species. The concept takes advantage of variation in vital rates among subpopulations to increase individual fitness, improve species status, and maintain metapopulation structure for long-term resiliency. We simulate two-stage translocation scenarios for conserving the Hawaiian monk seal Monachus schauinslandi, a critically endangered species which exhibits highly variable juvenile, but consistently favorable adult, survival rates. Moving young seals from areas of lower to higher juvenile survival and subsequently returning them to their source site once they have reached an appropriate age improves population reproductive value. We present a decision framework for implementing two-stage translocation in a manner that minimizes risks while increasing the likelihood of desired outcomes. Two-stage translocation may be effective for metapopulations of other rare species which exhibit variation in vital rates among subpopulations and a life-stage bottleneck due to factors that are not amenable to in situ mitigation.
\end{abstract}

KEY WORDS: Translocation · Metapopulation · Hawaiian monk seal

\section{INTRODUCTION}

Translocation has been defined as 'the humanmediated movement of living organisms from one area, with release in another' (IUCN/SSC 2013, p. 2). A variety of related terms including 'reintroduction', 'reinforcement/supplementation', and 'conservation/ benign introductions' are distinguished by the aims of the action and whether the destination habitat is part of the species' current or historic range (IUCN in press). Recently, in anticipation of climate change impacts, the traditional lexicon of translocation has expanded to include 'ecological replacement', 'assisted colonization', and 'community construction' (Seddon 2010).

The term 'relocation' typically connotes removing nuisance animals, those that find themselves out of their normal habitat or in places where they may interact with humans in undesirable ways. Thus, translocation and relocation, while they both amount to shifting animals around, suggest distinct objectives. The focus of translocation is on establishing or increasing the population at the site to which animals are taken. In contrast, the crux of relocation is resolving issues at the site from which the animals are taken.

Here, we develop a translocation approach, which is grounded in both Caughley's (1994) 'declining-population paradigm' and metapopulation theory. Caughley (1994) maintained that the strongest element of applied conservation biology was the diagnosis of, and subsequent intervention to mitigate, declines in small populations. Ideally, the cause of decline is identified and in situ treatment (e.g. trapping invasive predators or restoring degraded habitat) allows 
the population to recover. However, when the cause of decline is not amenable to in situ treatment, creative and unconventional conservation schemes are required. A remarkably successful example is 'Operation Nest Egg', in which brown kiwis were collected and raised in captivity and on predator-free islands, then released back into their natal area once they had achieved a body size sufficient to escape predation by introduced carnivores (Colbourne et al. 2005, Robertson et al. 2011).

Metapopulations are composed of multiple subpopulations with some degree of demographic independence, though linked by migration (Hanski \& Simberloff 1997). Asynchrony in demographic parameters among subpopulations has been promoted as a buffer against extinction (Allen et al. 1993, Roughgarden 1998). Strategic use of translocation has been explored (primarily theoretically through modeling and quantitative decision frameworks) as a tool for increasing the resilience and persistence of endangered species by fostering healthy metapopulation structure (Lubow 1996, Rout et al. 2007). Similar matters have been modeled in the context of designing optimal reintroduction strategies (reviewed in Armstrong \& Reynolds 2012). Implementing these metapopulation management concepts in practice is quite rare. A good example is the effort to manage African wild dogs using translocation to mimic natural dispersal and maintain gene flow among subpopulations that would otherwise be isolated (DaviesMostert et al. 2009).

We develop a translocation scheme to conserve metapopulations of endangered species. The underlying concept is to take advantage of variation in vital rates among subpopulations in order to improve population status. We developed these ideas in the context of Hawaiian monk seal Monachus schauinslandi conservation, though variations of our proposal may be applied beneficially in other systems. If the proposed program is initiated for Hawaiian monk seals, sufficient data for complete project evaluation will not be obtained for several years. Here, we present to the applied conservation science community both the general twostage translocation concept as well as our proposed risk-averse experimental approach for its application in Hawaiian monk seal conservation.
The Hawaiian monk seal is structured in a metapopulation consisting of 8 Northwestern Hawaiian Islands (NWHI) subpopulations, together comprising roughly $85 \%$ of total abundance; the remainder is distributed amongst the main Hawaiian Islands (MHI) (Fig. 1). Approximately 1100 seals occur in subpopulations ranging from roughly 50 to 200 seals each. NWHI abundance has recently been declining by an estimated $4 \%$ per year, while the MHI subpopulation has been growing by about $7 \%$ annually (Baker et al. 2011b).

The monk seal subpopulations display varying degrees of demographic independence but are linked through regional environmental correlation as well as migration (Baker \& Thompson 2007, Schultz et al. 2011, Baker et al. 2012). Effective migration has apparently been sufficient to preclude any discernible genetic population structure, such that the species is comprised of a single panmictic population (Schultz et al. 2011). Therefore, translocation raises no concerns about mixing distinct genetic groups. Spatial patterns of disease exposure likewise do not currently preclude translocation (Littnan et al. 2006), though disease monitoring is ongoing.

Numerous threats were identified in the Recovery Plan for the Hawaiian Monk Seal (NMFS 2007), but the primary cause of the NWHI decline appears to be food limitation leading to high juvenile mortality (Baker 2008). Periods of low juvenile survival in the NWHI have resulted in degraded age structures exhibiting an over-representation of newborns and older seals, with few juveniles and young adults. Conversely, juvenile survival is higher in the MHI (Fig. 2). Notably, monk seal survival rates after 2 to 3 yr of age are relatively uniform and high in all subpopulations.

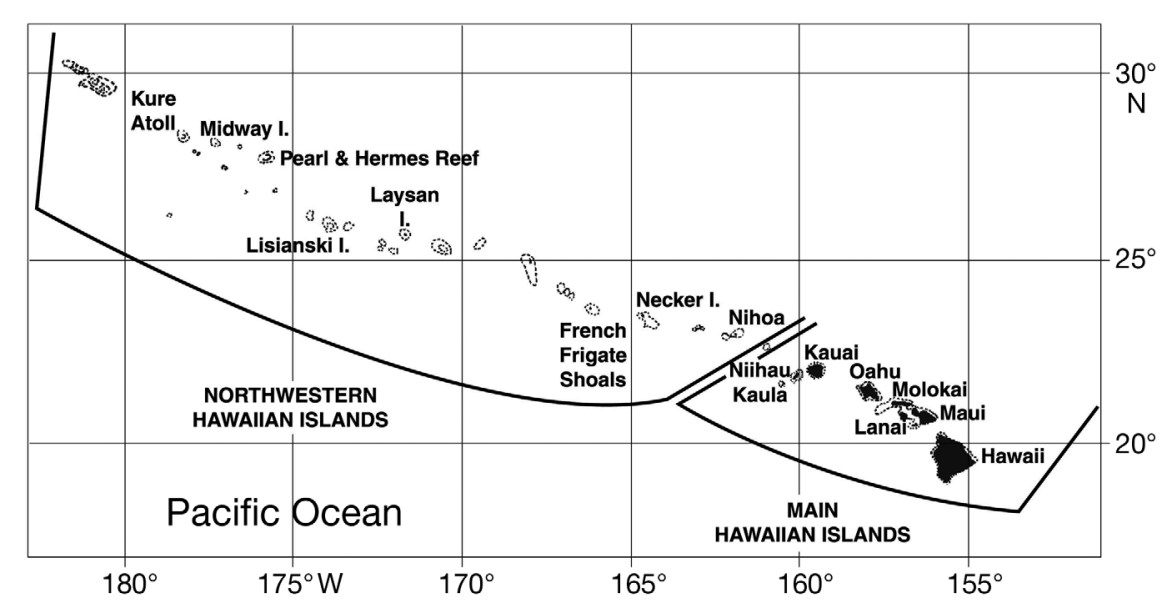

Fig. 1. The Hawaiian Archipelago 


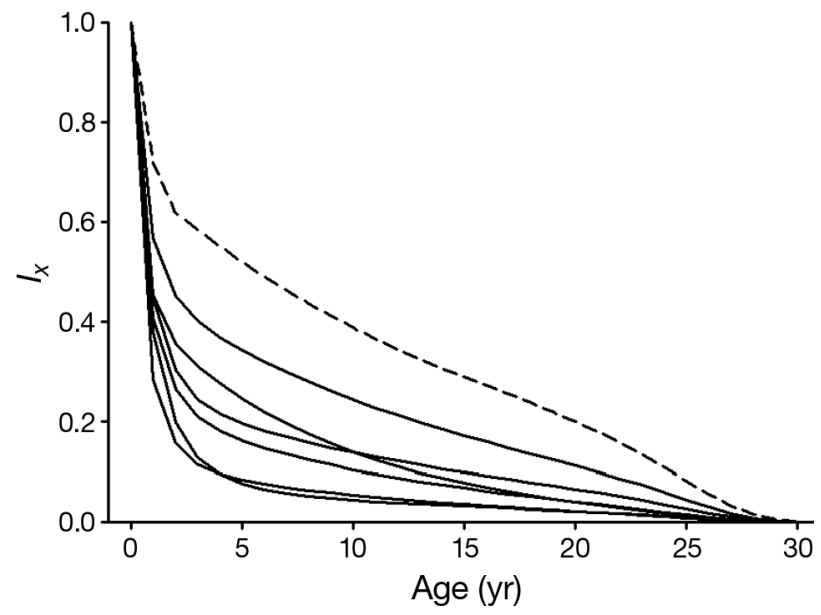

Fig. 2. Cumulative survivorship curves $\left(l_{x}\right)$ for the 6 Northwestern Hawaiian Islands subpopulations (solid lines), based upon recent (2006-2008) rates, and all available data in the main Hawaiian Islands (dashed line). From Baker et al. (2011b)

Insufficient prey availability to young seals may be mediated through poor or variable productivity, competition with other predators (Baker \& Johanos 2004, Parrish et al. 2008, Baker et al. 2012), or both. Regardless of the ultimate cause(s), asynchronously varying juvenile survival has been observed across the monk seal's range. Because the diagnosis indicates that periodic deficiencies in the ecosystem lead to the demise of young monk seals, there are no apparent in situ remedies. A variety of measures have been profitably applied to alleviate monk seal mortality from entanglement in marine debris, male seal aggression, and shark predation. However, these efforts have proven insufficient; actions that address prey availability for juvenile seals may be required to reverse the population decline.

\section{METHODS}

\section{Basic concepts and approach}

Translocation has proven to be a useful tool for Hawaiian monk seal conservation. Baker et al. (2011a) reviewed 247 cases and found that translocated monk seals typically remained in the subpopulations where they were placed and enjoyed survival rates equal to seals at the destination site. We propose a two-stage translocation scheme to achieve the following objectives: (1) increase individual fitness; (2) improve the species' status; and (3) maintain meta-population structure for long-term resiliency.
Our fundamental concept is to use translocation to address mismatches between local environmental conditions and the distribution of animals among subpopulations. For example, some pups wean at subpopulations where they experience high mortality, apparently largely due to insufficient prey resources. Thus, many of these neonates perish, whereas, because of spatial variability among sites, they might have survived elsewhere. This would be tolerable if the monk seal population were large and if environmental conditions were consistently more favorable. The current situation, however, is not sustainable because abundance is low and declining in much of the species' range. Further, adverse conditions have prevailed for more than a decade in some subpopulations, and natural dispersal occurs too slowly to effectively redistribute animals to sites with favorable conditions.

Translocation is a tool that could mitigate population decline by artificially accelerating dispersal of young females from areas of lower to higher survival. This approach could achieve the first 2 objectives above (increase individual fitness and improve species status). Yet, if translocations are conducted at an appreciable scale for a sufficient number of years, some potentially negative consequences must be addressed. For example, source populations may become unacceptably depleted or exhibit skewed sex ratios (for efficiency, only females would be translocated). Moreover, moving too many seals to favorable sites might adversely impact vital rates through density dependence. For these reasons, a 'secondstage' translocation is proposed, which would return animals to their natal areas once they pass the juvenile mortality bottleneck. This would achieve the third objective, maintaining metapopulation structure, and address metapopulation considerations that have been raised in the context of reintroductions (Armstrong \& Seddon 2008).

Present conditions are more favorable in the MHI than in the NWHI, but while juvenile survival in the NWHI tends to be lower, those seals that reach adulthood enjoy survival rates comparable to those in the MHI (Baker \& Thompson 2007, Baker et al. 2011b). At present, then, the most effective scenario would likely involve moving weaned female pups from the NWHI to the MHI in order to increase the proportion surviving (first stage of translocation). Once seals reach an age at which survival rates are favorable everywhere, they would be returned to their natal site (second-stage translocation). The latter will serve to rebalance population distribution to avoid excessive depletion of source subpopulations, ensure the 
MHI does not become over-populated, and prevent potential problems associated with male-biased sex ratios at source sites (Johanos et al. 2010). Further, the return translocation would fortify subpopulation age structures, positioning them to exploit eventually improved conditions and achieve more rapid growth. Without the second stage of the translocation process, source subpopulations could become sufficiently depleted that population growth would be very slow, even if environmental conditions improved.

Whereas the preceding translocation scenario (i.e. NWHI to MHI and return) is suggested by recent conditions, future trends in survivorship will likely favor other approaches. The underlying translocation strategy remains consistent, but specifics are adaptable to prevailing demographics and environmental conditions.

\section{Decision framework}

Three features of the two-stage translocation concept include (1) the program will occur over several years; (2) environmental and, perhaps in smaller subpopulations, demographic stochasticity lead to variable and unpredictable monk seal survival rates over time and space; and (3) outcomes of this strategy are uncertain, and there is potential for unintended, undesirable outcomes. Recognizing this, we emphasize the design, execution, and evaluation of twostage translocation supported by a decision framework and simulation modeling, which reflect an effort to consider all relevant inputs to inform actions and foresee and minimize the risks of undesirable outcomes.

Annually estimated survival rates and age-sex structures will largely determine when, and between which subpopulations, translocations should be conducted. Monitoring of both translocated and nontranslocated individuals will allow project evaluation, informing subsequent steps and reducing uncertainties of simulations.

Risks are inherent in any intervention in wild populations, but can be minimized through program design, intensive monitoring and evaluation, and a decision framework which is informed by new data. We identified potential risks and corresponding mitigation measures associated with twostage translocation (Table 1). We subsequently constructed a decision framework to guide execution of the program, whereby each decision point has inputs designed to optimize benefits while minimizing risk (Fig. 3, see Supplement 1 at www. int-res.com/articles/suppl/n021p033_supp.pdf for a narrative description).

\section{Simulations}

We used an existing Hawaiian monk seal stochastic simulation model to evaluate expected outcomes from a set of translocation scenarios. Details of the model structure and mechanics are provided in Harting (2002). It is a mechanistic, stochastic, metapopulation model with provisions for handling uncertainties in input parameters and modeled processes. The model capitalizes on more than 2 decades of demographic and life history data. It provides options for simulating management interventions, including translocations. The model includes the option for density-dependent adjustment of demographic rates, but this option was not included in modeled scenarios for 3 reasons. First, we assessed the effects of translocations after a relatively short time horizon (10 yr), during which density dependence would be unlikely to exert strong influence. Second, simulating density dependence would lessen our ability to isolate the effects of translocations, as results would partially reflect the neutralizing force of density dependence on the population trajectory. Third, we do not know the precise manner in which density dependence operates on monk seal populations, so that any implementation of such effects could be misleading.

For modeling the NWHI, age- and subpopulationspecific survival rates were derived from fitting the Siler survivorship curve (a 5-parameter function with separate terms to represent competing risks associated with juvenile, mature, and senescent life stages; Siler 1979) to observed Jolly-Seber estimates from the most recent 3 yr of data (Jolly 1965, Seber 1965). Age-specific reproductive rates were estimated using pooled data from 1990 to the present (cf. Harting et al. 2007). Vital rate uncertainty was incorporated in simulations by randomly sampling parameters from the variance-covariance matrices associated with parameter fitting. Survival and reproductive rate estimation for the MHI are described in Baker et al. (2011b). The model determines survival and reproduction stochastically for each individual by Bernoulli sampling (testing a uniform random number in the range $[0,1]$ against the age-specific vital rate). Migration is also determined the same way using movement rates for each age class based on tag resightings. Each simulation 
Table 1. Risks and concerns that may affect the outcome and evaluation of two-stage translocations in Hawaiian monk seals

\begin{tabular}{|c|c|c|}
\hline Issue & Risk or concern & Mitigating factors \\
\hline $\begin{array}{l}\text { Depletion of source } \\
\text { subpopulations }\end{array}$ & $\begin{array}{l}\text { Removals from source sites may deplete } \\
\text { subpopulations, such that: } \\
\text { (1) Seals no longer play a functional role in } \\
\text { the system } \\
\text { (2) Competitors occupy the seal's niche } \\
\text { and inhibit population re-establishment } \\
\text { (3) Empty environment could be a wasted } \\
\text { opportunity for growth if intraspecific } \\
\text { competition is low } \\
\text { (4) Few animals remain for monitoring } \\
\text { source site conditions }\end{array}$ & $\begin{array}{l}\text { Depletion should be short-term and moderate because } \\
\text { 3-yr-olds will be returned to the source population. } \\
\text { This should ultimately increase the source population } \\
\text { after return translocations commence. Should intra- } \\
\text { specific competition lessen at the source site, juvenile } \\
\text { survival should consequently increase, which will re- } \\
\text { duce the survival differential between sites and auto- } \\
\text { matically regulate further weaned pup translocations. }\end{array}$ \\
\hline $\begin{array}{l}\text { Development of } \\
\text { male-biased } \\
\text { sex ratios }\end{array}$ & $\begin{array}{l}\text { Removal of female pups will eventually } \\
\text { manifest in male-biased sex ratios, } \\
\text { leading to increased male aggression } \\
\text { toward adult females and juveniles. }\end{array}$ & $\begin{array}{l}\text { Translocated females will be returned to source sites } \\
\text { prior to sexual maturity. They should have higher sur- } \\
\text { vival than (non-translocated) males. Two-stage trans- } \\
\text { location should result in some female bias for affected } \\
\text { cohorts. If translocated females fare worse than their } \\
\text { male counterparts, weaned pup translocations would } \\
\text { be suspended. This could result in male bias for a few } \\
\text { cohorts, but would affect a small portion of the total } \\
\text { population. }\end{array}$ \\
\hline $\begin{array}{l}\text { Capacity of host } \\
\text { site to absorb } \\
\text { immigrants }\end{array}$ & $\begin{array}{l}\text { Overshooting carrying capacity could } \\
\text { cause the host population to crash. }\end{array}$ & $\begin{array}{l}\text { Host-site demographics will be closely monitored, } \\
\text { especially for declining juvenile survival. If this is ob- } \\
\text { served, differential survival between source and host } \\
\text { sites would decrease, so that further translocations } \\
\text { slow or cease. }\end{array}$ \\
\hline $\begin{array}{l}\text { Translocated seal } \\
\text { survival }\end{array}$ & $\begin{array}{l}\text { Weaned pups may not fare as well as } \\
\text { natives at their host site. } \\
\text { Returnees may not survive as well as } \\
\text { those that have remained at their natal } \\
\text { site from birth. }\end{array}$ & $\begin{array}{l}\text { Survival outcomes will be closely monitored. } \\
\text { Experience has shown that weaned pups are amen- } \\
\text { able to translocation and have survival rates indistin- } \\
\text { guishable from pups born at release sites. } \\
\text { If returnee post-release effects are sufficiently severe, } \\
\text { further translocations would cease. }\end{array}$ \\
\hline Infectious disease & $\begin{array}{l}\text { Translocationg may result in faster } \\
\text { spreading disease than would occur } \\
\text { naturally. }\end{array}$ & $\begin{array}{l}\text { Health screening of all translocated seals, coupled } \\
\text { with appropriate quarantine of returnees, will mini- } \\
\text { mize risk of transporting infectious agents. Disease } \\
\text { surveillance will be ongoing throughout the species } \\
\text { range to detect emerging disease outbreaks }\end{array}$ \\
\hline
\end{tabular}

was initialized with the 2010 age-sex distributions for each subpopulation.

We simulated two-stage translocation scenarios involving French Frigate Shoals (FFS) and the MHI. These sites were selected based on the survival differential estimated from data through 2010. FFS has exhibited poor juvenile survivorship (proportionate survival from birth to Age $3 \mathrm{yr}$, denoted as $l_{3}=0.137$ ) compared with the $\mathrm{MHI}\left(l_{3}=0.641\right)$. We simulated the collection of 10 female pups annually for $5 \mathrm{yr}$ at FFS and subsequent release at the MHI. Consistent with negligible captive mortality in the past, the simulated number of seals released was the same as the number collected (Baker et al. 2011a). Once simulated pups were released, the model applied a first-year survival adjustment to translocatees relative to native-born seals at the release site. This Stage-1 adjustment accounted for differences among subpopulations in weaning condition (axillary girth), which is known to influence first year survival (Baker 2008). Weaned MHI pups are fatter and exhibit higher survival than in the NWHI (Baker \& Johanos 2004, Baker et al. 2011b). Therefore, NWHI pups translocated to the MHI would not necessarily enjoy the average survival rate of native pups, but rather the survival rate of similar-sized pups in the MHI.

We derived a provisional Stage-1 survival adjustment value from the relationship between girth and survival in the MHI. We fitted a logistic regression to the binary response (survived at least $1 \mathrm{yr}$, or not) for 


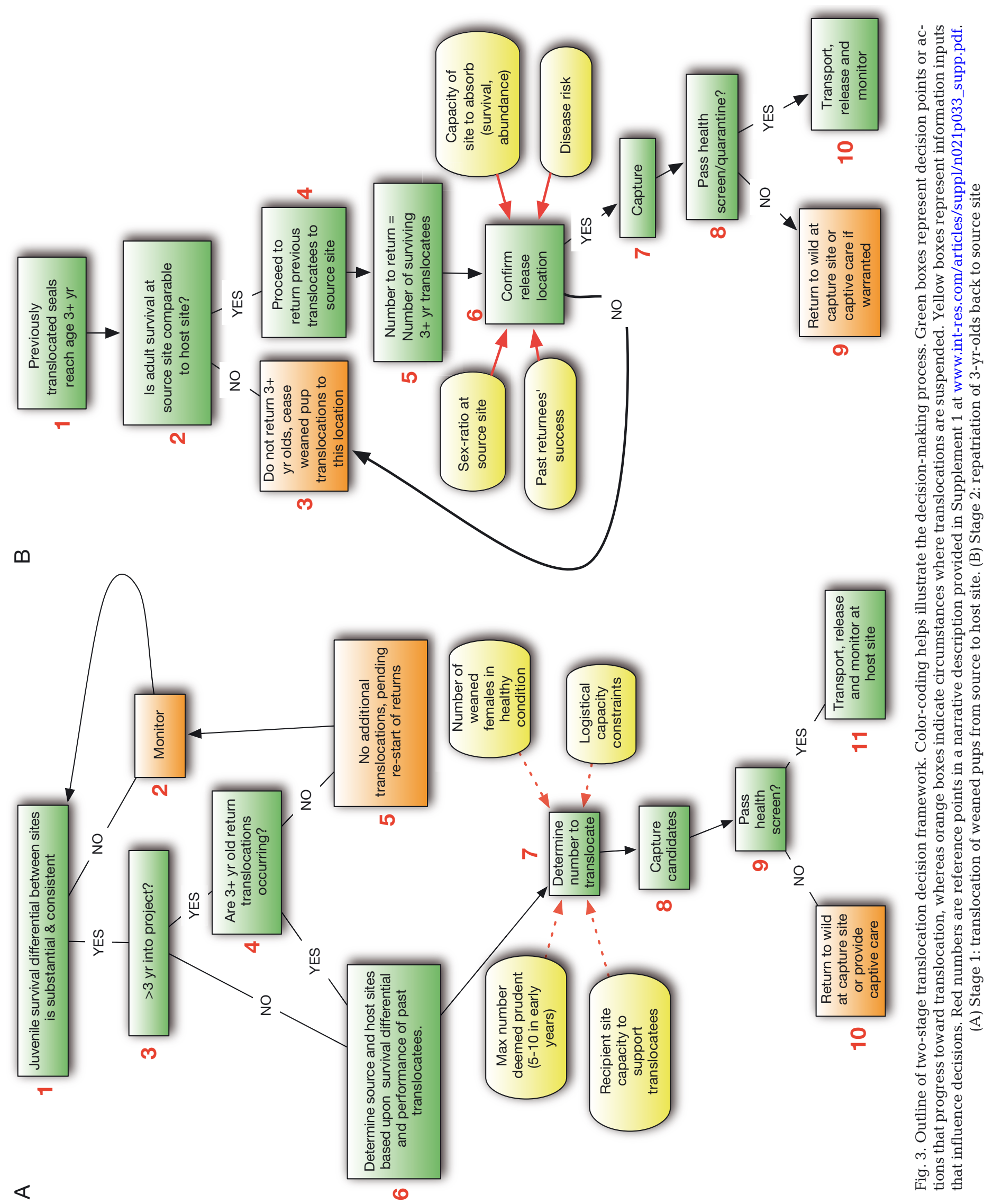


74 MHI pups born and measured through 2008 (cf. Baker 2008). The resulting relationship, despite being positive, was not statistically significant $(\mathrm{p}=$ 0.53), likely for 2 reasons. First, MHI pups are generally in very good condition, so there were few thin animals in the sample. Second, foraging conditions appear to be favorable in the MHI, which may ameliorate selection against smaller pups (Baker 2008).

Despite the lack of significance, we used the fitted relationship to predict the expected survival for average-sized FFS pups in the MHI. Seventy weaned pups born during the 2007 to 2009 period at FFS averaged $103.7 \mathrm{~cm}$ in girth. The logistic regression equation predicted a survival rate of 0.69 for pups this size. The overall survival rate of pups born in the MHI is 0.77 (Baker et al. 2011b), so that a provisional adjustment for FFS pups translocated to the MHI is $0.69 / 0.77=0.90$. When making survival adjustments this value was multiplied by native survival for some translocation scenarios. Additional scenarios were run using no survival adjustment for the first year after release at the host site. This is consistent with the observation that seals translocated in the past have enjoyed survival rates indistinguishable from those of native-born seals (Baker et al. 2011a).

Following the first year after release, translocated seals shared the same survival rate as native-born seals until Age $3 \mathrm{yr}$, at which time their return to their source site was simulated. At this stage, post-release effects on survival were applied to represent differential success relative to non-translocated seals during the first year after release (Armstrong \& Reynolds 2012). The appropriate magnitude for this postrelease effect is uncertain, but multiple factors might steer this adjustment in opposing directions. Returning seals will initially be unfamiliar with the new environment and might require some time to orient to the habitat, as well as to different prey, competitor, and predator assemblages. Increased mortality due to stress of captivity may occur for seals of this age. In contrast, seals returning from the favorable host site should be larger and healthier than seals that developed at the source site, conferring a survival benefit on the former.

Due to these uncertainties, we simulated both scenarios with no post-release survival effect, and with a multiplier of 0.71 relative to native seal survival. The latter was based upon a previous project in which compromised pups were cared for in captivity and later released to the wild (Gilmartin et al. 2011). Firstyear post-release survival of those seals was lower by a factor of 0.71 compared with native seals. That project differed in many ways from two-stage translocation such that the 0.71 multiplier may be overly severe; it is, however, the only possibly relevant information available. The 2 values used (1.00 and 0.71 ) bracket a plausible range for post-release effects. Two survival adjustment values at each of 2 stages yield 4 translocation scenarios plus a baseline (no translocation) scenario (Table 2).

\section{Evaluation metrics}

Proper metrics are needed to evaluate simulated translocation outcomes. Total population abundance or realized growth rate from the first to final years of the simulations could be misleading metrics because they fail to account for unfavorable age structures. In some monk seal subpopulations, protracted periods of low juvenile survival have led to ageing breeding populations and dwindling cohort sizes. The inertia in these age structures essentially guarantees future declines, which can mask improvements to popula-

Table 2. Effects of simulated two-stage translocation of the Hawaiian monk seal between French Frigate Shoals (FFS) and the main Hawaiian Islands on the source subpopulation (FFS). Survival adjustments apply to the first year after initial release at host site (Stage 1) to account for body condition differences among subpopulations, and first year after return to the source site (Stage-2 post-release effect). Adjustment values were multiplied by the survival rates of resident (non-translocated) seals. Evaluation metrics include final total abundance $(N)$, population reproductive value $\left(V_{\text {pop }}\right)$, total number of mature females $\left(N_{\mathrm{f}, \text { mature }}\right)$, survivorship from weaning to Age $4 \mathrm{yr}\left(l_{\mathrm{w} 4}\right)$, and the intrinsic rate of growth for the life table representing the translocated seals $\left(\lambda_{\text {trans }}\right)$. Values in parentheses are 5 th and 95th percentiles of simulation results. N/A: not applicable

\begin{tabular}{|c|c|c|c|c|c|c|}
\hline Scenario & $\begin{array}{l}\text { Survival adjustment } \\
\text { (Stage 1, Stage 2) }\end{array}$ & $N$ & $V_{\text {pop }}$ & $N_{\mathrm{f}, \text { mature }}$ & $l_{\mathrm{w} 4}$ & $\lambda_{\text {trans }}$ \\
\hline Baseline & N/A & $93(61,131)$ & $165(100,244)$ & 26 & 0.123 & 0.916 \\
\hline No adjustments & $1.00,1.00$ & $112(78,151)$ & $263(169,375)$ & 43 & 0.434 & 0.991 \\
\hline Stage 1 adjustment only & $0.90,1.00$ & $111(77,151)$ & $252(162,360)$ & 41 & 0.391 & 0.985 \\
\hline Stage 2 adjustment only & $1.00,0.71$ & $105(71,144)$ & $228(144,326)$ & 37 & 0.310 & 0.969 \\
\hline Both adjustments & $0.90,0.71$ & $104(71,143)$ & $221(138,325)$ & 36 & 0.279 & 0.964 \\
\hline
\end{tabular}


tion status if measured only in terms of total abundance or growth rate.

We favor a metric associated with population age structure. Age-specific reproductive value ( $v_{X}$, Eq. 1) reflects the probable future reproductive output of an individual female now of Age $x$ in terms of newborn equivalents. This value is given by:

$$
V_{X}=\frac{\lambda^{x}}{l_{X}} \sum_{i=x}^{\max } \frac{\phi_{i}}{\lambda^{i}}
$$

where $\lambda$ is the intrinsic growth rate, $l_{X}$ is the survivorship to Age $x$, and $\phi_{X}$ is the age-specific net maternity function $\left(l_{X} m_{X}\right)$.

Reproductive value represents the relative demographic contributions expected from individuals of different ages. It incorporates information on both the likelihood of survival to each reproductive age, as well as the expected reproductive output of an individual of Age $x$ and all future ages. It is less useful for comparing among different populations since it is scaled in terms of newborns for the unique life table applicable to a given site. For monk seal subpopulations, $V_{X}$ attains a maximum at around 5 to 7 yr of age, but varies in maximum value from 6 (FFS) to less than 3 newborn equivalents (MHI) (Fig. 4). The difference is largely attributable to the fact that newborn pups at FFS stand little chance of reaching reproductive maturity, whereas the prospects for MHI pups are relatively high.

Whereas $V_{X}$ is a property of the life table, population reproductive value ( $V_{\text {pop }}$ ) extends the concept by incorporating information on the current population size and age-sex composition. This parameter is the sum of the age-specific reproductive values for all of the females currently in the population:

$$
V_{\text {pop }}=\sum_{X=0}^{\max } V_{X} n_{X}
$$

where $V_{X}$ is the age-specific reproductive value of an individual of Age $x$, and $n_{x}$ is the number of individuals of Age $x$ currently in the population. $V_{\text {pop }}$ is analogous to the potential energy stored in the population, which is likely to translate into future production. This metric is appropriate for Hawaiian monk seal populations. Two-stage translocation may not achieve a major improvement in total population abundance. However, by targeting age-structure adjustments, the population can be fortified so that it is capable of more rapid growth should environmental conditions improve. Two-stage translocation is designed to increase the number of females in those age classes having the highest $v_{X}$. In aggregate, those additional females will increase $V_{\text {pop }}$.
While $V_{\text {pop }}$ is arguably the most meaningful metric for our purposes, we also examine a variety of others that are more intuitive. These include final total abundance $(N)$, the total number of mature females $\left(N_{\mathrm{f}, \mathrm{mature}}\right), l_{\mathrm{X}}$ of affected age classes, and the intrinsic rate of growth for the life table representing the translocated seals $\left(\lambda_{\text {trans }}\right)$.

\section{RESULTS}

\section{Effects at the host site}

Because seals were returned to their source site at Age 3 yr, the simulated effects of the translocations at the host site were ephemeral (Fig. 5A). Further, the translocated seals were returned prior to attaining reproductive maturity and therefore produced no pups at the host site. Consequently, final abundance at the host site was unchanged by translocations, but compared with the baseline trajectory, the mean population trajectory was elevated during the years (1 to 8) when translocated seals were temporarily residing at the host site.

\section{Effects at the source site}

For all scenarios, the source population (FFS) was initialized at the 2010 population size of 194 seals. Simulation results are summarized in Table 2. Abundance declined under all simulation scenarios. In the baseline scenario (Table 2, Fig. 6), the abundance dropped to 93 seals at the

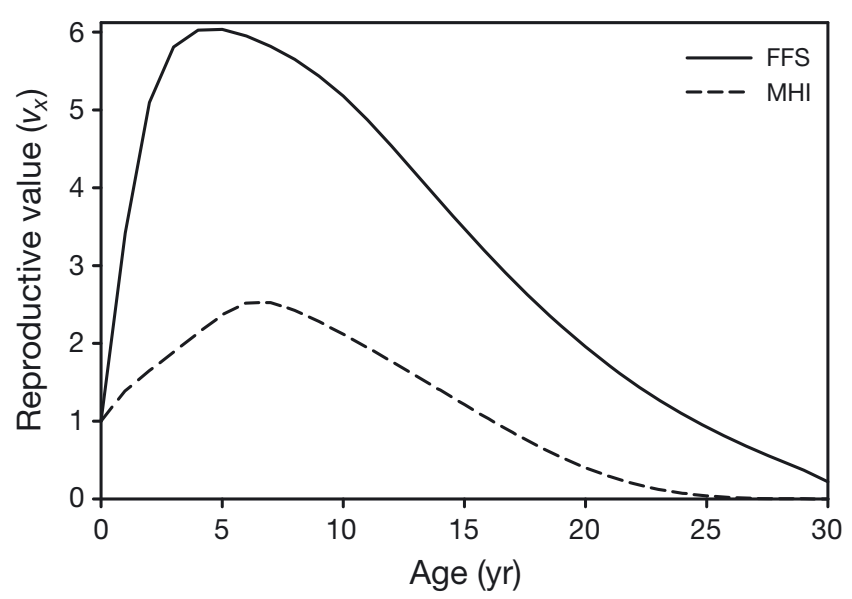

Fig. 4. Contrasting age-specific reproductive value $\left(v_{x}\right)$ curves for French Frigate Shoals (FFS) and main Hawaiian Islands (MHI) monk seals 


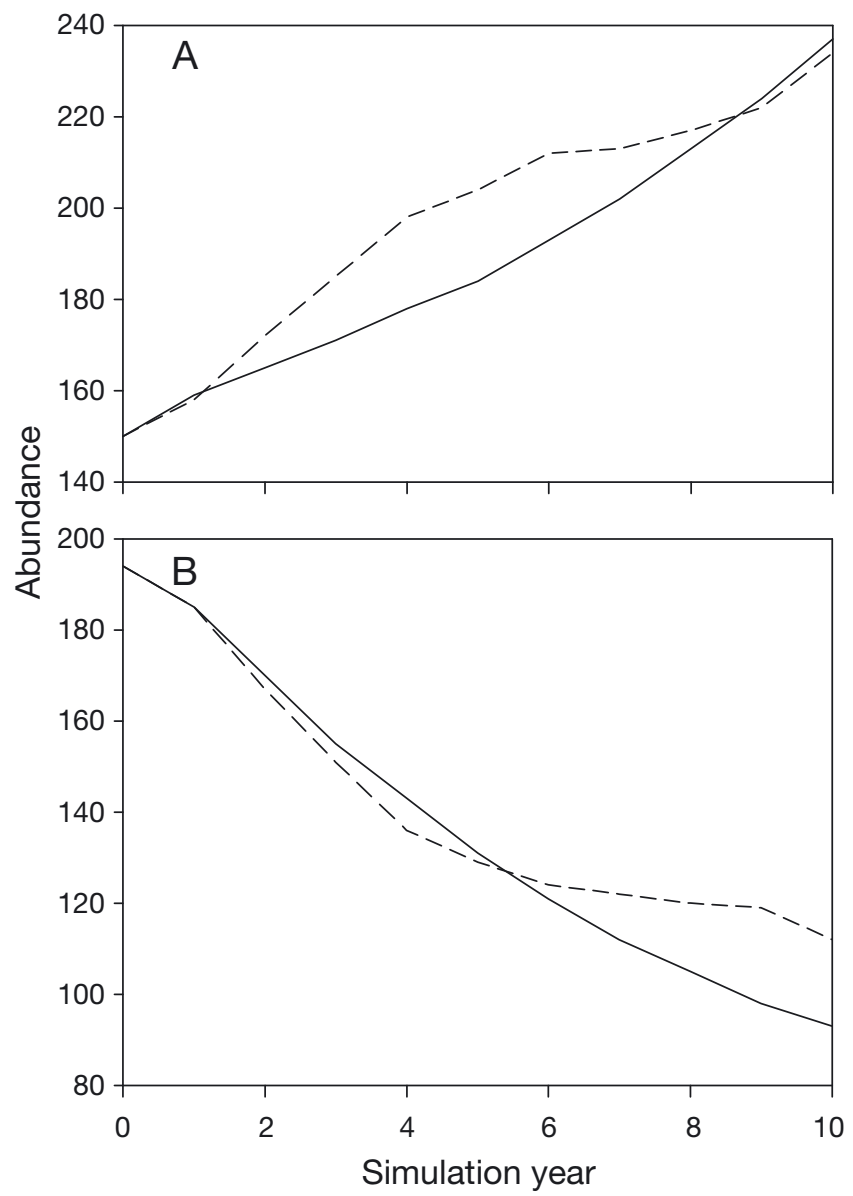

Fig. 5. Simulation trajectories at the (A) host (main Hawaiian Islands [MHI]) and (B) source (French Frigate Shoals [FFS]) sites for a representative translocation scenario. Lines represent mean abundance at each time step, with translocation (dashed lines) and without translocation (solid lines). At the host site there is an ephemeral elevation in mean abundance during the years the project is underway

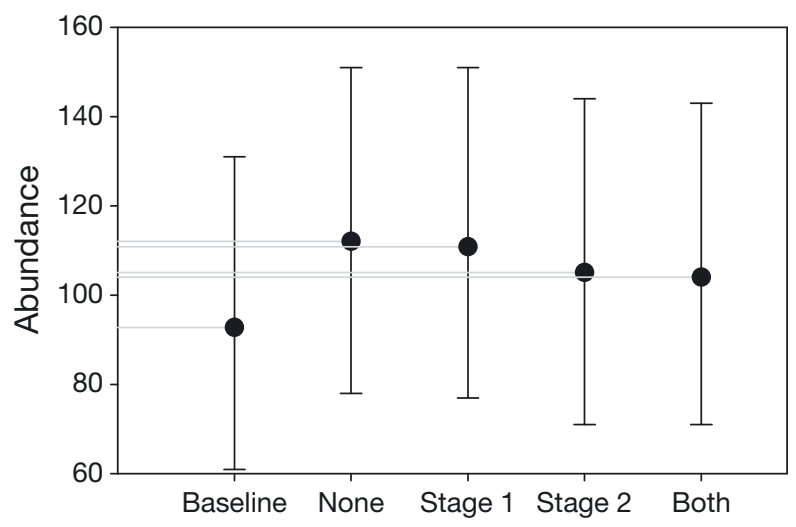

Fig. 6. Mean abundance (with 5th and 95th percentiles) of Hawaiian monk seals at the source site (French Frigate Shoals) for the baseline and 4 translocation scenarios. Scenarios differ in the survival adjustments applied, as described in Table 2. Grey reference lines along the vertical axis facilitate comparison of the various scenarios

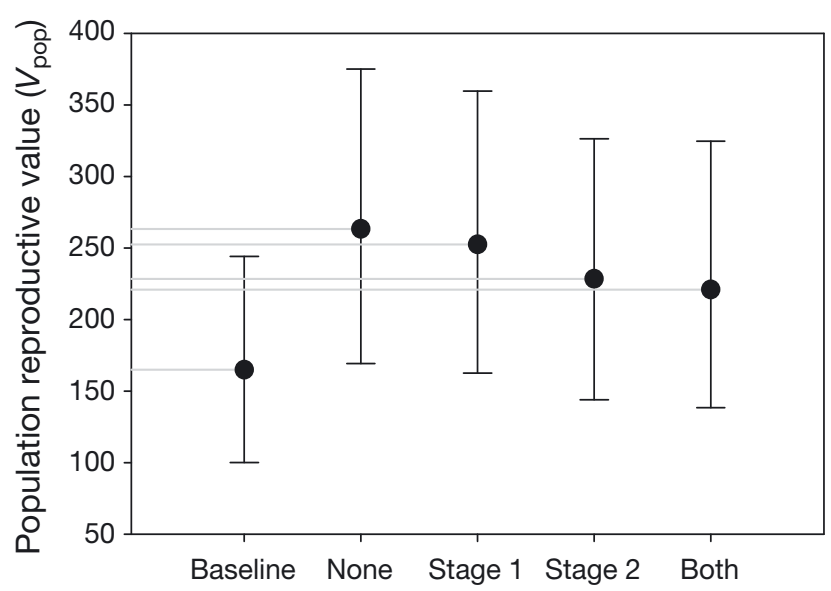

Fig. 7. Hawaiian monk seal population reproductive value ( $V_{\text {pop }}$ with 5th and 95th percentiles) at the source site (French Frigate Shoals) for the baseline and 4 translocation scenarios. Scenarios differ in the survival adjustments applied, as described in Table 2. Grey lines as in Fig. 6

end of the 10-yr projection (52\% decline). The projected decline was largely driven by loss of older seals and declining births. Although the benefits derived from translocations were insufficient to fully compensate for the forecast population decline, the final abundance with translocation ranged from 104 to 112 seals, depending on which survival adjustments were applied.

Simulated translocations achieved more impressive effects on population reproductive value $\left(V_{\mathrm{pop}}\right)$. However, as with final abundance, the simulated translocations did not offset the expected decline from all other factors (Fig. 7). Initially, the FFS $V_{\text {pop }}$ is approximately 360 newborn equivalents. Under the baseline scenario, $V_{\text {pop }}$ is expected to decline to less than 165 newborn equivalents. In contrast, under the translocation scenarios, final $V_{\text {pop }}$ ranged from 221 to 263 newborn equivalents.

The translocation effects may also be viewed as improving the proportional change in $V_{\text {pop }}$ from Year 1 to Year 10 of the scenarios. With no intervention, in $10 \mathrm{yr}$ the FFS subpopulation is expected to have only about $46 \%$ of the reproductive potential of the initial population. With translocation, between 63 and $75 \%$ of $V_{\text {pop }}$ is preserved.

Focusing on the benefits to just the translocated seals, as opposed to overall subpopulation status, survival from weaning to Age $4 \mathrm{yr}\left(I_{\mathrm{w} 4}\right)$ rose from 0.12 in the baseline scenario to $0.28-0.43$ depending upon the combination of survival adjustments applied. Similarly, a life table improvement for the translocated seals is also evident as $\lambda_{\text {trans }}$ rose from 0.92 under the baseline to $0.96-0.99$. 


\section{DISCUSSION}

\section{Simulation results}

Most previously published models designed to inform metapopulation management through translocation or reintroduction have evaluated modeled scenarios in a metapopulation population viability analysis context, with projections from several decades to over 1000 yr (e.g. Lubow 1996, Swart \& Lawes 1996, Pedrono et al. 2004, Bretagnolle \& Inchausti 2005, Kuemmerle et al. 2011). Actual estimates of extinction risk from such models may be highly suspect due to limited data for estimating input parameters and their error (e.g. Akcakaya \& Burgman 1995, Beissinger \& Westphal 1998), as well as the inherent uncertainty in predicting so far into the future (e.g. Ludwig 1999, Coulson et al. 2001). Nevertheless, extinction risk estimates may provide a basis for ranking management options (e.g. Carroll et al. 2003).

Our modeling approach differed from those above, both in terms of simulation duration and evaluation metrics. We simulated 5 yr of translocations and evaluated outcomes after projecting only $10 \mathrm{yr}$ into the future. We are confident that the range of model results are quite reliable on this time scale given the high-quality demographic data available for monk seals. In contrast, we would place far less stock in projections decades or centuries into the future. Moreover, while our ultimate goal is to reduce extinction risk, we believe that a metric such as population reproductive value more directly addresses the goal of fortifying subpopulation age structure.

The FFS subpopulation will likely decline in abundance and reproductive capacity with or without translocation due to the dismal current state of the subpopulation's age-sex structure. Simulations indicate that two-stage translocation could moderate the decline and reinforce the population. Simulation scenarios were designed to illustrate the range of benefit that might be realized from two-stage translocation if conducted for a realistic management time frame $(5 \mathrm{yr})$. Longer-term metapopulation management could yield greater benefits.

We have characterized two-stage translocation as fortifying a declining subpopulation so that it is better able to capitalize on future improved environmental conditions. If in fact conditions do not improve, then two-stage translocation is of limited value, in that the strategy only slows inevitable decline. Betting on a more favorable environment in the future, then, is the crux of the argument for pursuing two-stage translocation. Fortunately, more than half a century of monitoring monk seals makes a compelling case that conditions have fluctuated dramatically with asynchronous trends among subpopulations. At some sites, decadal-scale North Pacific climate variability appears to have strongly influenced past monk seal population trends (Baker et al. 2012). Regardless of the drivers, the historical record supports the expectation that where conditions are poor, they will eventually improve, and vice versa. Further, we recognize that key environmental drivers are not amenable to human manipulation. Thus, the goal of metapopulation management with two-stage translocation is to minimize deterioration of subpopulation status during unavoidable periods of decline and to foster natural population recovery when conditions are favorable.

\section{Uncertainty in post-release effects}

Given the uncertainty about the magnitude of postrelease effects, we considered how large a survival penalty translocated seals could incur before their survival matched that of non-translocated seals at the source site. This threshold value can be estimated from observed survival rates at the source and host sites. Given recent survival rates, seals translocated from FFS to MHI as pups and returned at Age $3 \mathrm{yr}$ would do better than non-translocated seals if their realized survival for the first year after return is at least $32 \%$ that of non-translocated seals (detailed calculation in Supplement 2 at www.int-res.com/ articles/suppl/n021p033_supp.pdf). This suggests that there is a sizable safety buffer even if the most severe post-release effect (0.71) used in the simulations was overly optimistic. The threshold value provides a reference for maintaining a standard of doing no harm with the proposed program.

\section{Generalization to other systems}

Two-stage translocation could be used to enhance other species of concern. Four conditions are sufficient to consider implementation of two-stage translocation. First, a metapopulation with spatial variation in vital rates is necessary so that it is more likely that there are sites with favorable conditions at any given time. Second, declines in particular subpopulations must be due to a bottleneck at a particular life stage, which can be circumvented by translocation (e.g. Colbourne et al. 2005). In contrast, if there is poor survival at all ages or overall reproductive failure, then two-stage 
translocation would not be beneficial. Third, there should be no insurmountable issues (i.e. genetic structure or disease risks) that would preclude moving animals among subpopulations. Fourth, the cost of translocation should be less than that of equally effective in situ intervention. This final condition is not required for two-stage translocation to be effective. However, translocation programs can be expensive, logistically challenging, and may involve social impediments, so that if threats can be mitigated in situ, this course will typically be more efficient.

Two-stage translocation would be a novel initiative for Hawaiian monk seals; therefore, uncertainties limit the precision of the estimated benefits that may accrue from its application. Foremost among those uncertainties are the effects of demographic and environmental stochastic variation in vital rates, and the magnitude of the potential post-release survival effects associated with translocations. Nevertheless, we maintain that in the context of small, declining populations, experimental trials of any such promising intervention strategy should be considered even in the face of potential risks. The associated uncertainties can only be resolved through strategic experimentation and project evaluation. The effort to conserve brown kiwis (Operation Nest Egg) is an excellent example, whereby methods were experimentally refined to achieve a significant net benefit to the species (Colbourne et al. 2005, Robertson et al. 2011). Adhering to a risk-averse decision framework limits the potential for over-commitment should failures occur. The alternatives - inaction or wellmeaning measures undertaken without experimental rigor - are far less likely to succeed.

Acknowledgements. In 2011, the Society for Conservation Biology convened a panel of experts to critically review twostage translocation. A white paper describing this conservation strategy for Hawaiian monk seals was the subject of the review and became the basis for this manuscript. We are grateful to the Society and the review panel (L. Gerber [Chair], J. Estes, A. Read, T. Gancos and L. Peavey) for their thoughtful, diligent, and timely input. We thank J. Ginsberg for his assistance in arranging the review. Comments by D. Armstrong greatly improved this manuscript. Finally, Dr. R. Braun initially conceived and articulated the idea of a temporary monk seal 'nursery'. His idea was the seed for the two-stage translocation concept proposed here.

\section{LITERATURE CITED}

Akcakaya HR, Burgman M (1995) PVA in theory and practice. Conserv Biol 9:705-707

> Allen JC, Schaffer WM, Rosko D (1993) Chaos reduces species extinction by amplifying local population noise. Nature 364:229-232
Armstrong DP, Reynolds MH (2012) Modelling reintroduced populations: the state of the art and future directions. In: Ewen JG, Armstrong DP, Parker KA, Seddon PJ (eds) Reintroduction biology: integrating science and management. Wiley-Blackwell, Oxford, p 165-222

Armstrong DP, Seddon PJ (2008) Directions in reintroduction biology. Trends Ecol Evol 23:20-25

Baker JD (2008) Variation in the relationship between offspring size and survival provides insight into causes of mortality in Hawaiian monk seals. Endang Species Res 5: 55-64

Baker JD, Johanos TC (2004) Abundance of the Hawaiian monk seal in the main Hawaiian Islands. Biol Conserv 116:103-110

Baker JD, Littnan CL (2008) Report of the Hawaiian Monk Seal Captive Care Workshop, Honolulu, Hawaii, 11-13 June 2007. Pac Is Fish Sci Center Admin Rep H-08-02. Pacific Islands Fisheries Science Center, National Marine Fisheries Service, NOAA, Honolulu, HI

Baker JD, Thompson PM (2007) Temporal and spatial variation in age-specific survival rates of a long-lived mammal, the Hawaiian monk seal. Proc Biol Sci 274: 407-415

Baker JD, Becker BL, Wurth TA, Johanos TC, Littnan CL, Henderson JR (2011a) Translocation as a tool for conservation of the Hawaiian monk seal. Biol Conserv 144: 2692-2701

> Baker JD, Harting AL, Wurth TA, Johanos TC (2011b) Dramatic shifts in Hawaiian monk seal distribution predicted from divergent regional trends. Mar Mamm Sci 27:78-93

Baker JD, Howell EA, Polovina JJ (2012) Relative influence of climate variability and direct anthropogenic impact on a sub-tropical Pacific top predator, the Hawaiian monk seal. Mar Ecol Prog Ser 469:175-189

Beissinger SR, Westphal MI (1998) On the use of demographic models of population viability in endangered species management. J Wildl Manag 62:821-841

Bretagnolle V, Inchausti P (2005) Modelling population reinforcement at a large spatial scale as a conservation strategy for the declining little bustard (Tetrax tetrax) in agricultural habitats. Anim Conserv 8:59-68

> Carroll C, Phillips MK, Schumaker NH, Smith DW (2003) Impacts of landscape change on wolf restoration success: planning a reintroduction program based on static and dynamic spatial models. Conserv Biol 17:536-548

> Caughley G (1994) Directions in conservation biology. J Anim Ecol 63:215-244

Colbourne R, Bassett S, Billing T, McCormick H, McLennan J, Nelson A, Robertson H (2005) The development of Operation Nest Egg as a tool in the conservation management of kiwi. DOC Research and Development Ser no. 259. Department of Conservation, Wellington

Coulson T, Mace GM, Hudson E, Possingham H (2001) The use and abuse of population viability analysis. Trends Ecol Evol 16:219-221

Davies-Mostert HT, Mills MGL, Macdonald DW (2009) A critical assessment of South Africa's managed metapopulation recovery strategy for African wild dogs. In: Hayward MW, Somers MJ (eds) Reintroduction of top-order predators. Wiley-Blackwell, Oxford, p 10-42

Gilmartin WG, Sloan AC, Harting AL, Johanos TC, Baker JD, Breese M, Ragen TJ (2011) Rehabilitation and relocation of young Hawaiian monk seals (Monachus schauinslandi). Aquat Mamm 37:332-341 
Hanski I, Simberloff D (1997) The metapopulation approach, its history, conceptual domain, and application to conservation. In: Hanski IA, Gilpin ME (eds) Metapopulation biology. Academic Press, San Diego, CA, p 5-26

Harting AL (2002) Stochastic simulation model for the Hawaiian monk seal. PhD dissertation, Montana State University, Bozeman, MT

Harting AL, Baker JD, Johanos TC (2007) Reproductive patterns of the Hawaiian monk seal. Mar Mamm Sci 23: 553-573

IUCN/SSC (2013) Guidelines for re-introductions and other conservation translocations, version 1.0. IUCN Species Survival Commission, Gland

Johanos TC, Becker BL, Baker JD, Ragen TJ, Gilmartin WG, Gerrodette $\mathrm{T}$ (2010) Impacts of sex ratio reduction on male aggression in the Critically Endangered Hawaiian monk seal Monachus schauinslandi. Endang Species Res 11:123-132

Jolly GM (1965) Explicit estimates from capture-recapture data with both death and immigration-stochastic model. Biometrika 52:225-247

Kuemmerle T, Perzanowski K, Akcakaya HR, Beaudry F and others (2011) Cost-effectiveness of strategies to establish a European bison metapopulation in the Carpathians. J Appl Ecol 48:317-329

Littnan CL, Stewart BS, Yochem PK, Braun R (2006) Survey for selected pathogens and evaluation of disease risk factors for endangered Hawaiian monk seals in the main Hawaiian Islands. EcoHealth 3:232-244

Lubow BC (1996) Optimal translocation strategies for enhancing stochastic metapopulation viability. Ecol Appl 6:1268-1280

Ludwig D (1999) Is it meaningful to estimate a probability of extinction? Ecology 80:298-310

Editorial responsibility: Brendan Godley,

University of Exeter, Cornwall Campus, UK
NMFS (National Marine Fisheries Service) (2007) Recovery plan for the Hawaiian monk seal (Monachus schauinslandi), 2nd revsn. National Marine Fisheries Service, Silver Spring, MD

Parrish FA, Marshall GJ, Buhleier B, Antonelis GA (2008) Foraging interaction between monk seals and large predatory fish in the Northwestern Hawaiian Islands. Endang Species Res 4:299-308

Pedrono M, Smith LL, Clobert J, Massot M, Sarrazin F (2004) Wild-captive metapopulation viability analysis. Biol Conserv 119:463-473

Robertson HA, Colbournes RM, Graham PJ, Miller PJ, Pierce RJ (2011) Experimental management of brown kiwi Apteryx mantelli in central Northland, New Zealand. Bird Conserv Int 21:207-220

Roughgarden J (1998) Primer of ecological theory. Prentice Hall, Englewood Cliffs, NJ

> Rout TM, Hauser CE, Possingham HP (2007) Minimise longterm loss or maximise short-term gain? Optimal translocation strategies for threatened species. Ecol Model 201:67-74

Schultz JK, Baker JD, Toonen RJ, Harting AL, Bowen BW (2011) Range-wide genetic connectivity of the Hawaiian monk seal and implications for translocation. Conserv Biol 25:124-132

Seber GAF (1965) A note on the multiple-recapture census. Biometrika 52:249-259

> Seddon PJ (2010) From reintroduction to assisted colonization: moving along the conservation translocation spectrum. Restor Ecol 18:796-802

Siler W (1979) A competing-risk model for animal mortality. Ecology 60:750-757

> Swart J, Lawes MJ (1996) The effect of habitat patch connectivity on samango monkey (Cercopithecus mitis) metapopulation persistence. Ecol Model 93:57-74

Submitted: October 1, 2012; Accepted: February 27, 2013

Proofs received from author(s): June 5, 2013 